TITLE:

\title{
The Function of the Four Types of Waving Display in Uca lactea: Effects of Audience, Sand Structure, and Body Size
}

\author{
$\operatorname{AUTHOR}(S)$ :
}

Muramatsu, Daisuke

\section{CITATION:}

Muramatsu, Daisuke. The Function of the Four Types of Waving Display in Uca lactea: Effects of Audience, Sand Structure, and Body Size. Ethology 2011, 117(5): 408-415

\section{ISSUE DATE:}

2011-03-01

URL:

http://hdl.handle.net/2433/197218

\section{RIGHT:}

This is the peer reviewed version of the following article: Muramatsu, D. (2011), The Function of the Four Types of Waving Display in Uca lactea: Effects of Audience, Sand Structure, and Body Size. Ethology, 117: 408-415, which has been published in final form at http://dx.doi.org/10.1111/j.1439-0310.2011.01884.x; This is not the published version. Please cite only the published version:; この論文は出版社版でありません。引用の際には出版社版をご確認ご利用くだ 
2 The function of the four types of waving display in Uca lactea: Effects of audience, sand structure, and body size

4

7 Department of Zoology, Graduate School of Science, Kyoto University Sakyo, Kyoto, 606-8502, JAPAN

9 muramatsu@ethol.zool.kyoto-u.ac.jp 
Multiple signals that convey different messages have been reported in many taxa, but relatively few studies have been made on such signals in invertebrates. In the present study, I investigated four types of claw-waving display used in the fiddler crab Uca lactea to test whether the displays have different functions. Three males with a sand structure beside their burrows (which can attract females) and three males without a sand structure were fenced in an opaque enclosure, and I videotaped their waving displays after releasing two burrowless males or two burrowless females to test the effects of audiences. (a) Lateral-circular waving tended to occur in enclosures with burrowless females and was performed frequently by males that had sand structures. (b) Lateral-flick waving was performed frequently by males without sand structures, and its frequency was positively correlated with the signaler's body size. (c) Rapid-vertical waving was observed frequently in enclosures with burrowless males, and its frequency was negatively correlated with the signaler's body size. (d) Circular waving tended to occur in enclosures with burrowless females and was performed frequently by males that had sand structures, and its frequency was positively correlated with the signaler's body size. In my previous study, lateral-circular waving was often seen in the breeding season and was mostly performed to female audiences, lateral-flick waving was frequently performed to neighboring resident males, rapid-vertical waving was performed mainly to intruding burrowless males, and circular waving did not have apparent audiences in most cases. Finally, I concluded that lateral-circular waving was used as a courtship display, lateral-flick waving was related to border disputes, rapid-vertical waving was used for burrow guarding, and circular waving was used to broadcast the signaler's general quality.

Key words: multiple signals; claw-waving display; fiddler crab; Uca lactea

\section{INTRODUCTION}

Animals in a broad range of taxonomic groups are known to use several distinct signals within a species (Narins \& Capranica 1976; Borgia 1995; Zuberbuhler 2000; Coleman et al. 2004; Elias et al. 2005; Hegyi et al.

53 2007; How et al. 2007; Bro-Jorgensen \& Dabelsteen 2008; Chaine \& Lyon 54 2008). A number of hypotheses have been proposed to explain why animals 
use multiple signals rather than just one (reviewed in Candolin 2003; Hebets \&

56

57

58

59

60

61

62

63

64

65

66

67

68

69

70

71

72

73

74

75

76

77

78

79

80

81

82 Papaj 2005; Bro-Jorgensen 2010). One intuitive explanation is that several signals are used to convey different messages (e.g., Zuberbuhler 2000; Candolin 2003; Chaine \& Lyon 2008). For example, sexual signals to mates and agonistic signals to rivals may be used to provide different information: sexual signals convey information about heritable genetic quality that contributes to offspring viability or attractiveness, and agonistic signals convey information about the signaler's current fighting ability (Bro-Jorgensen 2010).

In a previous study, I observed a natural population of the fiddler crab Uca lactea and found that males perform four distinct types of claw-waving display: lateral-circular, lateral-flick, rapid-vertical, and circular waving (see Muramatsu 2011 for behavioral descriptions). These displays may convey different messages, because the major audience and the seasonal occurrence patterns of the displays differed among waving types (Muramatsu 2011). I predicted that lateral-circular waving was used for courtship because this waving was often seen in the breeding season and was mostly performed to female audiences; lateral-flick waving was used in border disputes because this waving was frequently performed to neighboring resident males; and rapidvertical waving was used for burrow guarding because this waving was performed mainly to intruding burrowless males. Unlike these types of claw waving it was difficult to deduce the function of circular waving because this waving did not have obvious audiences in most cases. In the previous study, I predicted the functions of displays based on the audiences; however, the density of crabs and the sex ratio are not very stable during the crabs' active season (Muramatsu 2010a) and thus the encounter rate between signaler and some specific audiences may differ depending on the observation date. In the present study, I performed field experiments using an opaque enclosure to manipulate the density and sex of the audience around the signaler.

Each day, I removed all crabs except for six males from the enclosure, and then I released two burrowless males or females in the enclosure in order to observe their claw-waving in the presence of different audiences. I expected that courtship displays would be performed frequently in the enclosures with burrowless females, and that agonistic displays would be performed frequently in enclosures with burrowless males. Additionally, I examined the effects of the signaler's body size and the possession of a sand structure at the burrow entrance to test whether the male's condition affects his claw-waving. A sand structure is a type of courtship signal which helps to entice females into the 
burrow (Christy 1988a; Christy et al. 2003a, b). Several authors have suggested that the possession of a structure is costly for burrow residents (Backwell et al. 1995; Christy 1988a; Muramatsu 2009) and thus males that build structures may be in good condition (Backwell et al. 1995; Muramatsu 2010a). I predicted that males with a structure would perform courtship display more frequently than males without a structure because well-conditioned males would be capable of investing more time and energy in reproductive behavior.

9

\section{METHODS}

The study site was located at a dense colony of $U$. lactea, which was approximately $3500 \mathrm{~m}^{2}$ in area, centered on an intertidal mudflat in the estuary of the Yabusa River, Kagoshima, Japan (31 41' N, $\left.130^{\circ} 17^{\prime} \mathrm{E}\right)$. Crabs emerged from their burrows and were active on the mudflat surface during diurnal low tides, and approximately $45 \%$ of males constructed a sand structure at the entrance to their burrows (Muramatsu 2010b). In addition to these resident crabs, there were also some burrowless crabs (crabs that did not have their own burrow) wandering on the mudflat. All observations and experiments were conducted during spring tides in the breeding season, from June to August 2005 , except on the days with heavy rain.

Each day, a wooden enclosure $\left(50 \times 50 \mathrm{~cm}^{2}, 7 \mathrm{~cm}\right.$ high) was placed on the mudflat to fence in three males with a structure and three males without a structure. The enclosure was high enough so that the crabs were visually and physically isolated from the rest of the population. Crabs other than these six males were removed from the enclosure and their burrows were covered with soil to obliterate the entrances. In cases where the sand structures were constructed or destroyed, or irrelevant crabs emerged from the mudflat during the observation, the data were discarded.

To record the claw-waving of the males, the area within the enclosure was videotaped using a SONY DCR-TRV900 digital video camera on a tripod. Just before I started videotaping, I captured two burrowless males or two burrowless females at the study site and released them in the enclosure to investigate the effects of the audience on the frequency of claw-waving. Therefore, each enclosure holds either a pair of burrowless females or a pair of burrowless males. I started videotaping at the time of lowest tide, but the first 10 minutes were not used and next 10 minutes were used for data analyses 
because camera-setting inevitably disturbed crab behavior. After videotaping, the crabs in the enclosure were captured, sized, and marked with paint marker in order to avoid duplication. Crabs were captured by blocking the way back to their burrows using a wooden stick (see Muramatsu 2010a for details), and their carapace width was measured with calipers to the nearest $0.05 \mathrm{~mm}$. These videotaped spots were marked with 1-m-long, 4-mm-diameter wooden poles, which were inserted vertically into the sediment, leaving approximately 5 $\mathrm{cm}$ above the surface. The area surrounding the pole (approximately $3 \mathrm{~m}$ radius) was not used again.

Males of $U$. lactea perform four types of claw-waving: lateral-circular, lateral-flick, rapid-vertical, and circular waving (see Supporting Information 1, 2, 3 , and 4 , respectively). To count the strokes of each claw-waving on the video footage, I used the following criteria:

142 (a) Lateral-circular waving (combinations of slow lateral extension, quick flexion, 143 and circumduction of the large claw): I count each quick flexion as one stroke.

144 (b) Lateral-flick waving (quick lateral abduction to the audience): I count each 145 lateral whip motion as one stroke.

146 (c) Rapid-vertical waving (rapid dorso-ventral protraction and retraction): I count 147 each upward motion as one stroke.

148 (d) Circular waving (simple circumduction): I count each full circular motion as 149 one stroke.

150 I treated the stroke number during the observation (10 minutes) as the 151 frequency of claw-waving display. Note that waving frequency are not directory comparable among waving types because the time and energy required for one stroke would be different. Some types of waving tend to be performed at the entrance to the signaler's burrow. Therefore I recorded whether the signaler was in contact with the burrow entrance when they perform claw-waving.

The four types of claw-waving were separately counted and the effects of body size (carapace width of a focal male), sand structure (present or absent), and wanderers (burrowless males or females) on the frequency of each type of claw-waving were analyzed using glmmML (Generalized linear models with random intercepts; Broström 2009) implemented in the statistical

161 package $\mathrm{R}$ (R Development Core Team 2009). This glmmML function fits the 162 model using maximum likelihood and numerical integration via the Gauss-

163 Hermite quadrature. The Poisson distribution with log link function was used to 164 run count regression with each enclosure used as a random factor, and 165 Akaike's Information Criterion (AIC; see Akaike 1974) was used for model 
selection. I calculated AIC values for all possible models with or without the explanatory variables, and the model that yielded the smallest AIC value was selected as the best model to predict the frequency of claw-waving.

\section{RESULTS}

A total of 16 males in the five enclosures with burrowless females and 12 males in four enclosures with burrowless males were captured after they had been videotaped. The average carapace width was $14.14 \pm 0.27 \mathrm{~mm}$ (mean \pm SE) in males that had sand structures and $14.37 \pm 0.19 \mathrm{~mm}$ in males that did not have a structure.

(a) Lateral-circular waving

The best model for lateral-circular waving had presence of sand structure and sex of wanderer as explanatory variables (Table 1a, top row). Males that had structures performed this waving more frequently than males that did not have structures, and males with burrowless females performed this waving more frequently than males with burrowless males (Fig.1a; Table 1a, top row).

\section{(b) Lateral-flick waving}

The best model for lateral-flick waving had body size and presence of sand structure as explanatory variables (Table $1 b$, top row). The waving frequency of focal males was positively correlated with their body size, and males that did not have a structure performed this waving more frequently than males that had structures (Fig. 1b; Table 1b, top row).

No males performed lateral-flick waving at the entrance to their burrows (Table 2).

\section{(c) Rapid-vertical waving}

The best model for rapid-vertical waving had body size and sex of wanderer as explanatory variables (Table 1c, top row). The waving frequency of focal males was negatively correlated with their body size, and males with burrowless males performed this waving more frequently than males with burrowless females (Fig 1c; Table 1c, top row).

Compared to the three other types of waving, rapid-vertical waving tended to be performed at the entrance to the signalers' burrows (Table 2). 
(d) Circular waving

The best model for circular waving had body size, presence of sand structure, and sex of wanderer as explanatory variables (Table 1d). The waving frequency of focal males was positively correlated with their body size. Males that had structures performed this waving more frequently than males that did not have structures, and males with burrowless females performed this waving more frequently than males with burrowless males (Fig. 1d; Table 1d, top row). in courtship (e.g., Yamaguchi 1983, 2001; Burford et al. 2000; Pope 2000a, b;

217 Christy et al. 2001, 2002) and/or aggression (e.g., Crane 1958; Salmon 1965;

218 Zeil et al. 2006). Unlike other fiddler crab species, however, males of Uca

219 lactea perform four distinct types of claw-waving display (Muramatsu 2011).

220 Therefore, the four types of waving in $U$. lactea may have more specific

221 functions other than the general categories of courtship and aggression.

In my previous study, I predicted that lateral-circular waving would be used for courtship, because this waving was mostly performed to female audiences and was observed frequently in the breeding season (Muramatsu 2011). Additional data obtained in the present study showed that males in enclosures with burrowless females performed this waving more frequently than males with burrowless males, and males that had sand structures performed this waving more frequently than males without structures (Fig. 1a, Table 1a). Both results are consistent with the prediction that lateral-circular waving is related to courtship behavior.

By contrast, lateral-flick waving may be an offensive territorial display,

232 which is used in border disputes against neighboring resident crabs. This waving is frequently performed to both sexes of neighbor residents but is rarely performed to resident females in the breeding season (Muramatsu 2011). In $U$. lactea, resident females can be the rivals for males in border disputes, because residents of both sexes defend their territories around their burrows (Yamaguchi

237 \& Tabata 2004). In the breeding season, however, a resident female can also be a mating partner (Goshima \& Murai 1988; Yamaguchi 2001) and perhaps aggressive territorial displays would be suppressed in this period. In the present 
240 study, the frequency of lateral-flick waving was positively correlated with the

241 signaler's body size (Table 1b), suggesting that larger males were more

242 aggressive than smaller males. Meanwhile, males with sand structures

243 performed lateral-flick waving less frequently than males without structures

244 (Table 1b), possibly because the territories around burrows without sand

245 structures were more likely to be intruded into by other crabs and consequently

246 the burrow residents had to perform this waving frequently. Indeed, in the

247 absence of predators, burrows without sand structures were more frequently

248 visited by burrowless males than those with sand structures (Muramatsu,

249 unpublished data). This difference in the probability of approach could help to

250 explain why some studies have suggested that sand structures reduce

251 aggressive behaviors among resident males (Zucker 1974, 1981; but see

252 Christy 1988b).

253 Rapid-vertical waving may also be used as a territorial signal, but this

254 waving appeared to be used more defensively than lateral-flick waving. Rapid-

255 vertical waving was frequently performed at the entrances to the signalers'

256 burrow while no males perform lateral-flick waving at the burrow entrances

257 (Table 2) perhaps because rapid-vertical waving was used for burrow guarding

258 but not for border disputes. Because there are many burrowless crabs in the

259 field either looking for an empty burrow or attempting to take over a burrow

260 from other crabs (Pope 2005; Zeil et al. 2006), resident crabs may need to

261 defend their burrows from intruding crabs. Presumably, resident crabs are able

262 to deter intruders by performing this waving when they detect intruding crabs,

263 because it would be difficult for intruders to steal a burrow from residents when

264 the residents are aware of the intruder. It is noteworthy that the frequency of

265 rapid-vertical waving was negatively correlated with the signaler's body size

266 (Table 1c) and resident females also showed a similar claw-waving with their

267 small claws. This waving may not therefore be used to convey the signaler's

268 fighting ability or an aggressive message, but to show the signaler's awareness

269 of intruding burrowless crabs. In the present study, as expected, males with

270 burrowless males in an enclosure performed rapid-vertical waving more

271 frequently than the males with burrowless females (Table 1c). Although some

272 males performed this waving to burrowless females (Fig. 1c), most males

273 switched their display to lateral-circular waving when the burrowless females

274 got closer. Perhaps any burrowless crabs initially elicit precautionary behavior

275 of resident crabs until the residents recognize the sex of the intruder.

276 The most puzzling display of $U$. lactea is circular waving. Circular 
277 waving does not have an apparent audience in most cases and is frequently

278 observed prior to the breeding season (Muramatsu 2011). Likewise, some

279 species of fiddler crabs perform claw-waving in the absence of any specific

280 audience (Crane 1958; Christy et al. 2001; How et al. 2008) and these spontaneous displays may act as "broadcast" signals that are performed to a number of unspecified potential audiences (see Martins 1993; How et al. 2008). The results of the present study showed that the frequency of circular waving was positively correlated with the signaler's body size, and males with sand structures performed this waving more frequently than males without structures (Table 1d). Because both large body size and the possession of a structure are expected to be related to male quality, circular waving may be used to broadcast the signaler's general quality. In the present study, males with burrowless females performed circular waving more frequently than males with burrowless males (Table 1d), suggesting that the presence of burrowless females elicited circular waving more strongly. Hence, the baseline audience of this waving might be females, even though this waving does not seem to be directed to them. Given that circular waving was directed to females, this waving could be similar to lateral-circular waving. In my previous study, however, circular waving was most frequently performed prior to the breeding season, whereas lateral-circular waving was most frequently performed in the breeding season. Alternatively, circular waving in the present study might have been elicited by other males' waving. Males of $U$. mjoebergi are known to eavesdrop on the waving displays of nearby males (see Milner et al. 2010). In the present study, males in the enclosures with females may have performed circular waving frequently (Fig. 1d) because nearby males often showed lateralcircular waving toward burrowless females (Fig. 1a).

In conclusion, the results showed that lateral-circular waving may be used as a courtship display to attract females, lateral-flick waving may be an offensive territorial display relating border disputes, rapid-vertical waving may be a defensive territorial display used for burrow guarding, and circular waving may be a kind of broadcast signal to show the signaler's general quality. Although further investigation on the response of audiences may be needed to confirm that these four types of claw-waving are related to distinct functions, it

310 is clear that males of $U$. lactea use four types of claw-waving display in different

311 contexts. This kind of complex signaling may also be employed in other

312 invertebrate taxa, especially in group-living species that form mixed-sex

313 colonies. 


\section{ACKNOWLEDGEMENTS}

318 I would like to thank $\mathrm{H}$. Numata and A. Mori for valuable advice. I also thank E.

319 Nakajima for revising the English of the manuscript. This research was

320 financially supported in part by Global COE Program A06 to Kyoto University.

321

322

323

324

\section{LITERATURE CITED}

325

Akaike, H. 1974: A new look at the statistical model identification. IEEE Trans.

Automat. Contr. 19, 716-723.

327

328

Backwell, P. R. Y., Jennions, M. D., Christy, J. H. \& Schober, U. 1995: Pillar

329 building in the fiddler crab Uca beebei: evidence for a condition-dependent ornament. Behav. Ecol. Sociobiol. 36, 185-192.

331

332

Borgia, G. 1995: Complex male display and female choice in the spotted

333 bowerbird: specialized functions for different bower decorations. Anim. Behav. 49, 1291-1301.

335

336 Bro-Jorgensen, J. \& Dabelsteen, T. 2008: Knee-clicks and visual traits indicate

337 fighting ability in eland antelopes: multiple messages and back-up signals. BMC 338 Biol. 6, 47.

339

340 Bro-Jorgensen, J. 2010: Dynamics of multiple signalling systems: animal

341 communication in a world in flux. Trends Ecol. Evol. 25, 292-300.

343 Broström, G. 2009: Package 'glmmML'. http://cran.r-

344 project.org/web/packages/glmmML/glmmML.pdf.

346 Burford, F. R. L., McGregor, P. K. \& Oliveira, R. F. 2000: Response of fiddler

347 crabs (Uca tangeri) to video playback in the field. Acta Ethol. 3, 55-59.

349 Candolin, U. 2003: The use of multiple cues in mate choice. Biol. Rev. 78, 575350595. 
352 Chaine, A. S. \& Lyon, B. E. 2008: Intrasexual selection on multiple plumage ornaments in the lark bunting. Anim. Behav. 76, 657-667.

Christy, J. H. 1988a: Pillar function in the fiddler crab Uca beebei (2): competitive courtship signaling. Ethology 78, 113-128.

Christy, J. H. 1988b: Pillar function in the fiddler crab Uca beebei (1): effects on male spacing and aggression. Ethology 78, 53-71. production of a sexual signal: hoods and hood building by male fiddler crabs Uca musica. Behaviour 138, 1065-1083.

Christy, J. H., Backwell, P. R. Y., Goshima, S. \& Kreutera, T. 2002: Sexual selection for structure building by courting male fiddler crabs: an experimental study of behavioral mechanisms. Behav. Ecol. 13, 366-374.

Christy, J. H., Backwell, P. R. Y. \& Schober, U. 2003a: Interspecific

370 attractiveness of structures built by courting male fiddler crabs: experimental evidence of a sensory trap. Behav. Ecol. Sociobiol. 53, 84-91. hoods built by courting male fiddler crabs, Uca musica: test of a sensory trap hypothesis. Anim. Behav. 66, 89-94.

377 Coleman, S. W., Patricelli, G. L. \& Borgia, G. 2004: Variable female preferences drive complex male displays. Nature 428, 742-745.

379

380 Crane, J. 1958: Aspects of social behavior in fiddler crabs, with special 381 reference to Uca maracoani (Latreille). Zoologica 43, 113-130.

383 Elias, D. O., Hebets, E. A., Hoy, R. R. \& Mason A. C. 2005: Seismic signals are 384 crucial for male mating success in a visual specialist jumping spider (Araneae: 385 Salticidae). Anim. Behav. 69, 931-938.

387 Goshima, S. \& Murai, M. 1988: Mating investment of male fiddler crabs, Uca 
388

389

390

391

392

393

394

395

396

397

398

399

400

401

402

403

404

405

406

407

408

409

410

411 Muramatsu, D. 2009: To build or not to build - or to destroy burrow hoods in a

412

413

414 Muramatsu. D. 2010: Temporary loss of a sexual signal (claw loss) affects the 415 frequency of sand structure construction in the fiddler crab, Uca lactea. Ethol.

416 Ecol. Evol. 22, 87-93.

417

418 Muramatsu. D. 2010: Sand structure construction in Uca lactea (De Haan, 419 1835) is related to tidal cycle but not to male or female densities. Crustaceana 420 421

422 Muramatsu, D. 2011: For whom the male waves: four types of claw-waving 423 display and their audiences in the fiddler crab, Uca lactea. J. Ethol. 29, 3-8.

lactea. Anim. Behav. 36, 1249-1251.

Hebets, E. A. \& Papaj, D. R. 2005: Complex signal function:developing a framework of testable hypotheses. Behav. Ecol. Sociobiol. 57, 197-214.

Hegyi, G., Szigeti, B., Torok, J., \& Eens, M. 2007: Melanin, carotenoid and structural plumage ornaments: information content and role in great tits Parus major. J. Avian Biol. 38, 698-708.

How, M. J., Zeil, J. \& Hemmi, J. M. 2007: Differences in context and function of two distinct waving displays in the fiddler crab, Uca perplexa (Decapoda:

Ocypodidae). Behav. Ecol. Sociobiol. 62, 137-148.

How, M. J., Hemmi, J. M., Zeil, J. \& Peters, R. 2008: Claw waving display changes with receiver distance in fiddler crabs, Uca perplexa. Anim. Behav. 75, 1015-1022.

Martins, E. P. 1993: Contextual use of the push-up display by the sagebrush lizard, Sceloporus graciosus. Anim. Behav. 45, 25-36.

Milner, R. N. C., Jennions, M. D., \& Backwell, P. R. Y. 2010: Eavesdropping in crabs: an agency for lady detection. Biol. Lett. 6: 755-757. population of Uca lactea. J. Crustac. Biol. 29, 290-292. 
425 Narins, P. M. \& Capranica, R. R. 1976: Sexual differences in auditorysystem of

426 tree frog Eleutherodactylus coqui. Science 192, 378-380.

427

428 Pope, D. S.: 2000a: Video playback experiments testing the function of

429 clawwaving in the sand fiddler crab. Behaviour_so_

430 137, 1349-1360.

431

432 Pope, D. S. 2000b: Testing function of fiddler crab claw waving by manipulating 433 social context. Behav. Ecol. Sociobiol. 47, 432-437.

434

435

Pope, D. S. 2005: Waving in a crowd: fiddler crabs signal in networks. In:

436 Animal communication networks (McGregor, P. K., eds). Cambridge University

437 Press, Cambridge, pp. 247-262.

438

439

440 R Development Core Team 2009: R: A language and environment for statistical 441 computing. R Foundation for Statistical Computing, Vienna (http://www.R-

442 project.org.).

443

444 Salmon, M. 1965: Waving display and sound production in the courtship

445 behavior of Uca pugilator, with comparisons to U. mimax and U. pugnax.

446 Zoologica 50, 123-150.

447

448 Yamaguchi, T. 1983: Representative shore animals in the Amakusa Islands (1)

449 The fiddler crab, Uca lactea lactea (De Haan). Calanus 8, 25-32.

450

451 Yamaguchi, T. 2001: The mating system of the fiddler crab, Uca lactea

452 (Decapoda, Brachyura, Ocypodidae). Crustaceana 74, 389-399.

453

454 Yamaguchi, T. \& Tabata, S. 2004: Territory usage and defence of the fiddler

455 crab, Uca lactea (De Haan) (Decapoda, Brachyura, Ocypodidae). Crustaceana 456 77, 1055-1080.

457

458 Zeil, J., Hemmi, J. M., \& Backwell, P. R. Y. 2006: Fiddler crabs. Current Biology 459 16, 40-41.

460

461 Zuberbuhler, K. 2000: Interspecies semantic communication in two forest 
462 primates. Proceedings of the Royal Society of London B 267, 713-718.

463

464 Zucker, N. 1974: Shelter building as a means of reducing territory size in the

465 fiddler crab, Uca terpsichores (Crustacea: Ocypodidae). American Midland

466 Naturalist 91, 224-236.

467

468 Zucker, N. 1981: The role of hood-building in defining territories and limiting

469 combat in fiddler crabs. Anim. Behav. 29, 387-395.

470

471

472

473 
475 Table 1: Parameter estimates and AIC values in GLMMs for each waving.

476

\begin{tabular}{cccc} 
AIC & \multicolumn{4}{c}{ parameter estimate \pm SE } \\
\cline { 2 - 5 } & body size & sand structure & wanderer \\
& & (absent) & (male)
\end{tabular}

(a) Lateral-circular waving

\begin{tabular}{lcccc}
\hline 132.1 & $1.833 \pm 0.496$ & - & $-1.855 \pm 0.406$ & $-4.322 \pm 1.271$ \\
133.7 & $2.710 \pm 1.495$ & $-0.062 \pm 0.099$ & $-1.903 \pm 0.414$ & $-4.308 \pm 1.268$ \\
141.4 & $0.121 \pm 0.879$ & - & $-1.867 \pm 0.406$ & - \\
143.0 & $1.021 \pm 1.676$ & $-0.063 \pm 0.100$ & $-1.917 \pm 0.414$ & - \\
161.1 & $1.602 \pm 0.517$ & - & - & $-4.509 \pm 1.299$ \\
162.6 & $0.643 \pm 1.400$ & $0.067 \pm 0.091$ & - & $-4.530 \pm 1.306$ \\
170.9 & $-0.207 \pm 0.918$ & - & - & - \\
172.3 & $-1.209 \pm 1.611$ & $0.069 \pm 0.091$ & - & -
\end{tabular}

(b) Lateral-flick waving

\begin{tabular}{rrccc}
\hline 113.4 & $-4.099 \pm 2.286$ & $0.246 \pm 0.151$ & $0.597 \pm 0.287$ & - \\
114.2 & $-0.601 \pm 0.728$ & - & $0.710 \pm 0.281$ & - \\
114.5 & $-4.580 \pm 2.386$ & $0.244 \pm 0.152$ & $0.594 \pm 0.286$ & $1.110 \pm 1.203$ \\
115.2 & $-1.115 \pm 0.969$ & - & $0.706 \pm 0.280$ & $1.139 \pm 1.185$ \\
115.8 & $-5.020 \pm 2.321$ & $0.318 \pm 0.151$ & - & - \\
116.9 & $-5.567 \pm 2.434$ & $0.317 \pm 0.151$ & - & $1.242 \pm 1.328$ \\
118.7 & $-0.440 \pm 0.812$ & - & - & - \\
119.7 & $-1.019 \pm 1.077$ & - & - & $1.290 \pm 1.318$ \\
& & & & $1.038 \pm 0.552$ \\
$(\mathrm{c})$ Rapid-vertical waving & & - & - \\
\hline 1532 & $9.554 \pm 0.454$ & $-0.380 \pm 0.019$ & - & - \\
1533 & $10.008 \pm 0.420$ & $-0.379 \pm 0.019$ & $-0.047 \pm 0.036$ & $1.044 \pm 0.554$ \\
1533 & $9.548 \pm 0.456$ & $-0.378 \pm 0.019$ & $-0.047 \pm 0.036$ & - \\
1534 & $10.006 \pm 0.421$ & $-0.378 \pm 0.019$ & $-0.078 \pm 0.034$ & - \\
1980 & $4.637 \pm 0.318$ & - & $-0.078 \pm 0.034$ & $0.943 \pm 0.556$ \\
1980 & $4.219 \pm 0.372$ & - & - & $0.930 \pm 0.551$ \\
1983 & $4.616 \pm 0.315$ & - & - & -
\end{tabular}


(d) Circular waving

\begin{tabular}{lcccc}
\hline 200.1 & $-8.583 \pm 1.179$ & $0.775 \pm 0.073$ & $-0.584 \pm 0.138$ & $-1.365 \pm 0.773$ \\
200.9 & $-9.196 \pm 1.158$ & $0.776 \pm 0.073$ & $-0.587 \pm 0.138$ & - \\
217.3 & $-8.149 \pm 1.138$ & $0.738 \pm 0.070$ & - & $1.437 \pm 0.776$ \\
218.4 & $-8.797 \pm 1.119$ & $0.738 \pm 0.070$ & - & - \\
366.1 & $2.615 \pm 0.448$ & - & $-0.511 \pm 0.132$ & $-1.289 \pm 0.704$ \\
367.2 & $2.046 \pm 0.406$ & - & $-0.514 \pm 0.132$ & - \\
379.8 & $2.523 \pm 0.452$ & - & - & $-1.354 \pm 0.711$ \\
381.1 & $1.922 \pm 0.414$ & - & - & -
\end{tabular}

477

478 
480 Fig. 1: The frequency of waving in different conditions.

481 "wanderer" indicates the type of burrowless audience (females or males) in the

482 enclosure. "sand structure" indicates the possession of a sand structure

483 (present or absent).

484

485 Fig. 2: The proportion of waving performed at the burrow entrance.

486

487

488 

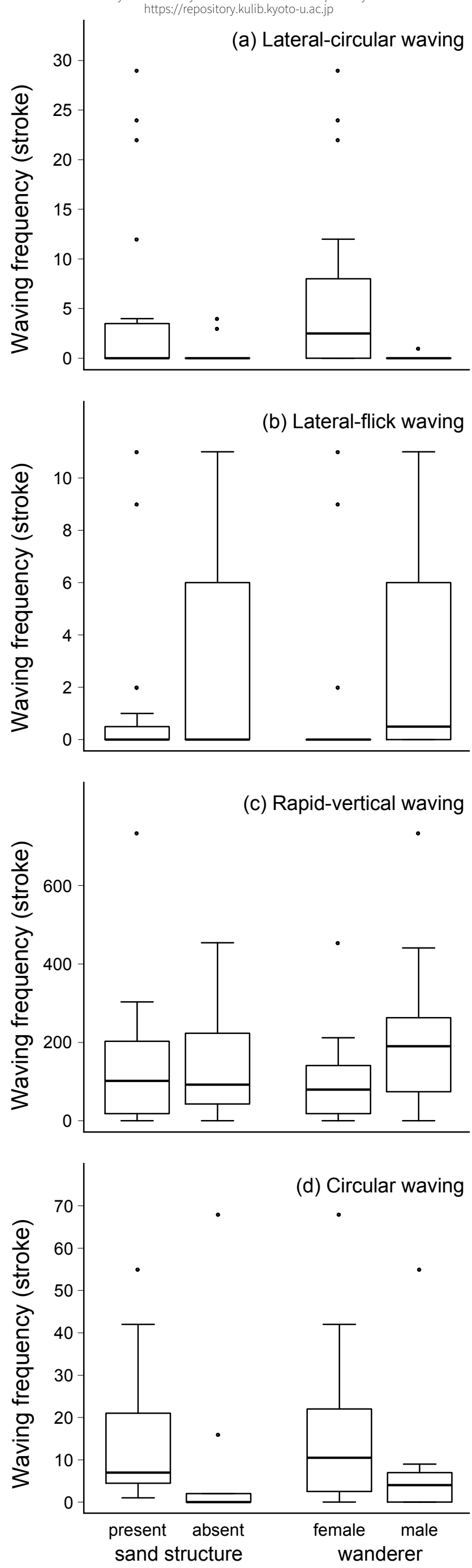

Fig. 1 


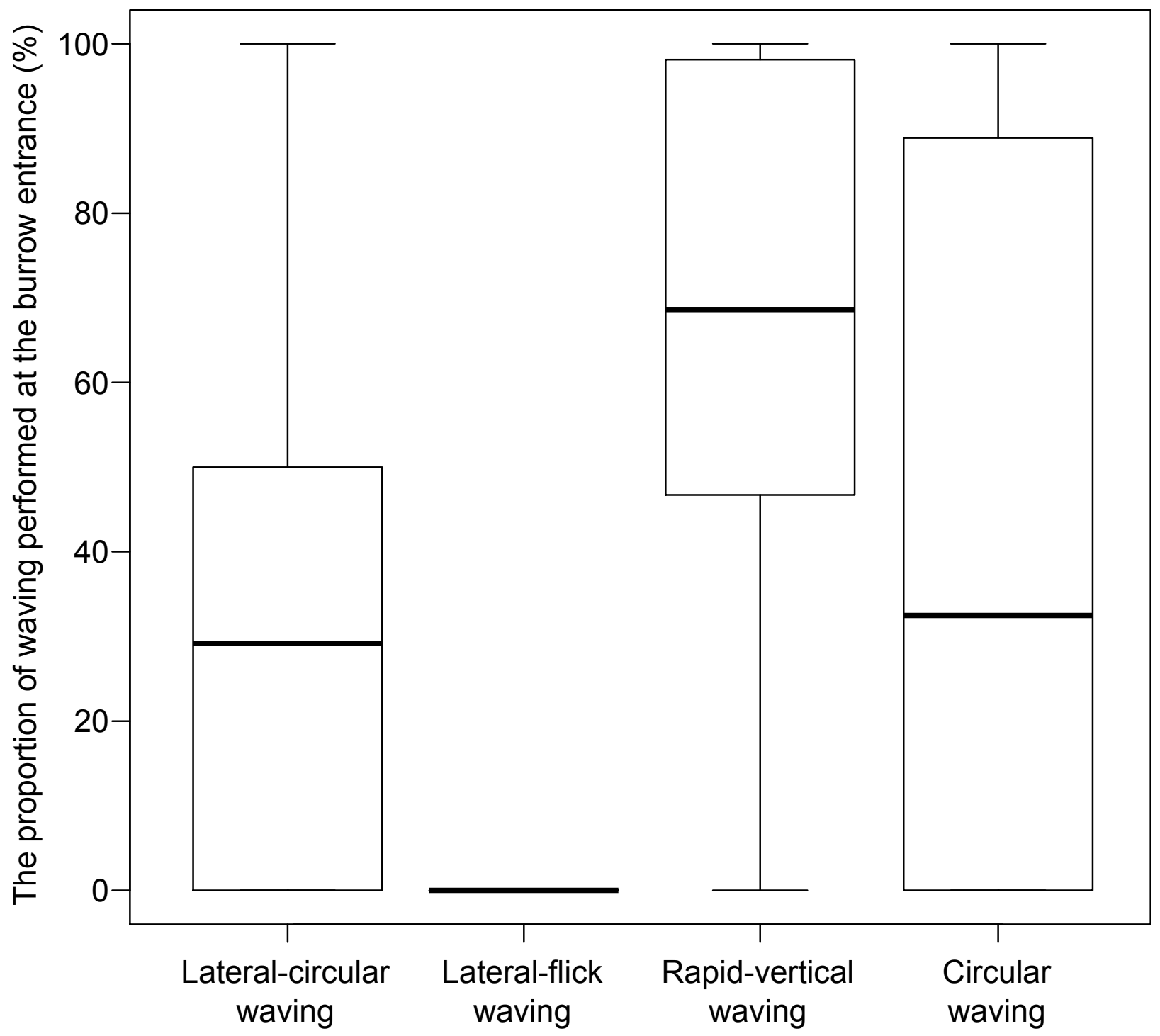

Fig. 2 